Portland State University

PDXScholar

$5-24-2017$

Billy Gryphen's House and Other Important Places: the Children's Geography of the Arcadia Neighborhood

Sophia K. Biddle

Portland State University

Follow this and additional works at: https://pdxscholar.library.pdx.edu/honorstheses

Let us know how access to this document benefits you.

Recommended Citation

Biddle, Sophia K., "Billy Gryphen's House and Other Important Places: the Children's Geography of the Arcadia Neighborhood" (2017). University Honors Theses. Paper 377.

https://doi.org/10.15760/honors.376

This Thesis is brought to you for free and open access. It has been accepted for inclusion in University Honors Theses by an authorized administrator of PDXScholar. Please contact us if we can make this document more accessible: pdxscholar@pdx.edu. 
Sophia K. Biddle

Portland State University

University Honors College

\title{
Billy Gryphen's House and Other Important Places: The Children's Geography of the Arcadia Neighborhood
}

\begin{abstract}
:
This paper explores how children ages 5 - 12 years old use, see, and value public space within the context of a fast-growing and rapidly gentrifying neighborhood in Portland, Oregon (USA). Using participatory action research and building upon Alison Clark's groundbreaking Mosaic Approach, this research aims to evaluate and amplify children's voices and opinions about their neighborhood. Drawing on children's artwork, photographs, and focus group interviews, this project assesses how children define "the neighborhood," how children participate in and make their own communities, and how children place value on public spaces. I argue that children's socio-spatial understanding of public space demonstrates complex social awareness, particularly when it comes to creating equitable communities. This research supports Chawla and Malone's (2003) conclusion that by integrating children's lived experiences and valid concerns, neighborhoods and communities can become safer, healthier, and more socially equitable. I argue that understanding and being responsive to the wants and needs of children when designing urban public spaces, particularly in rapidly changing cities such as Portland, can lead to desirable social outcomes, and describe a novel research methodology that can be used to achieve such an understanding.
\end{abstract}




\section{Acknowledgements:}

I'd like to thank to my thesis advisor, Amy Coplen, for her endless encouragement and for guiding me through this project. Special thanks to the Multnomah County Library and Nina Kramer for their support, and for providing space for this research. I especially want to thank the children who participated in this study. Without their brilliance and sincerity this research would not have been possible.

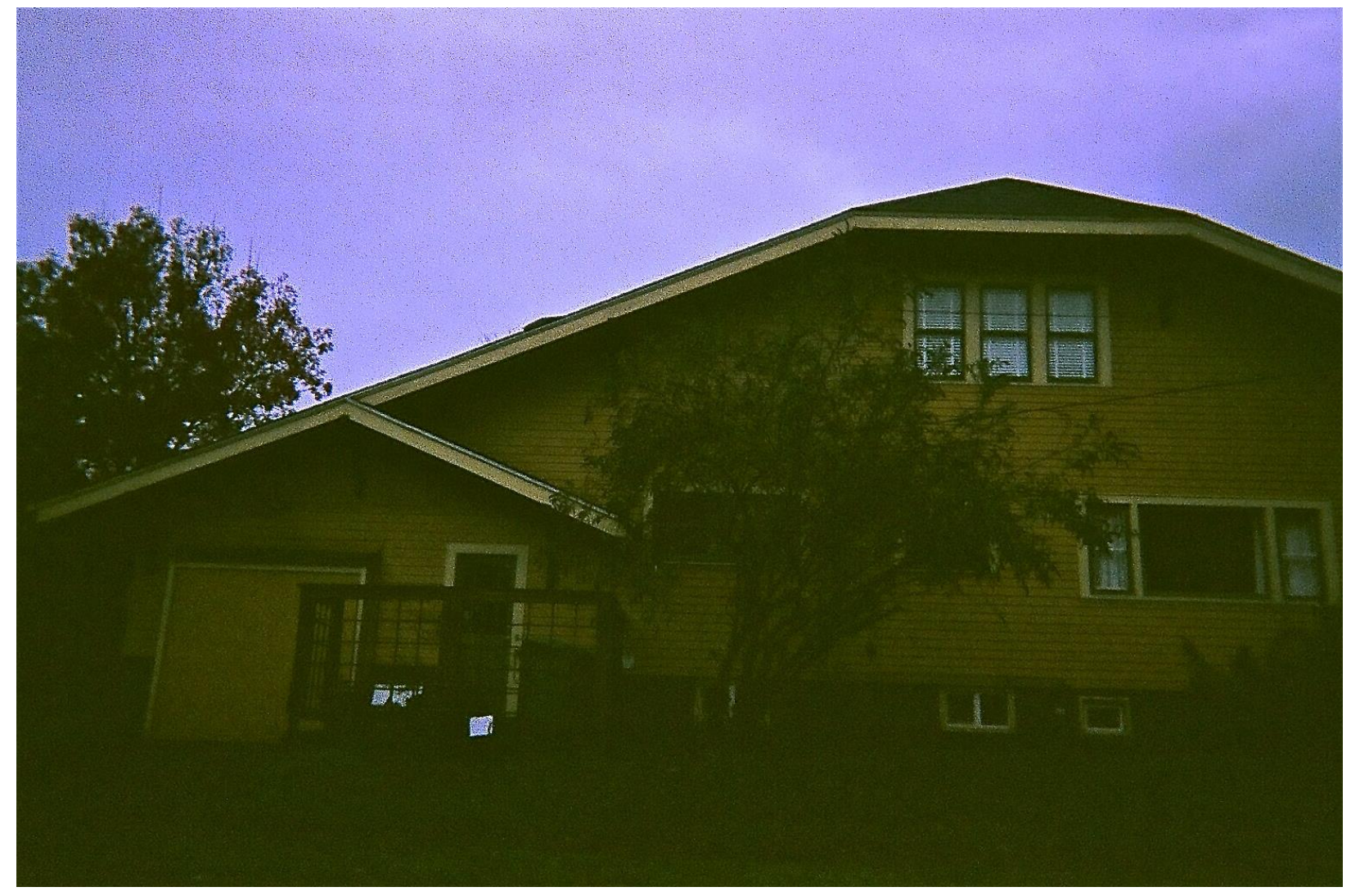

Billy Gryphen's House. Photo By: Silvie, age 9

Silvie, age 9: "Oh, gotta get a picture of that!"

Vasek, age 10: "Yeah, yeah!" 


\section{Introduction:}

Inadequate attention is paid to the needs and wants of children in designing high quality spaces in urban communities (Elsley, 2004). Children are entitled to environments that enable their rights to play, recreation, and participation in the cultural life of their societies (United Nations, Article 31, 1992). A key determinant for well functioning urban neighborhoods is the extent to which young people are integrated in community life (Bourke, 2016; Chawla and Malone, 2003). By creating neighborhoods that allow children and young people to be intertwined with their communities we create neighborhoods that are safer and more accessible for everyone (Chawla and Malone, 2003). With the U.S. federal government's failure to ratify the Convention on the Rights of the Child (CRC), it is imperative that states, cities, and towns do their part to protect the rights of their child residents (Mehta, 2015). One aspect of protecting children's rights is creating neighborhood environments that are accessible and responsive to children.

This research aims to evaluate and amplify children's voices. I worked with 21 local children ages 5 -12 years old to understand how children define and navigate "the neighborhood," participate in and help to create community, and construct value for neighborhood spaces. I collected data by using Clark’s (2004) Mosaic Approach, a form of Participatory Action Research tailored towards children, in an evolving urban neighborhood in Portland, Oregon. A total of 19 children drew maps of their communities while participating in open-ended, focus group style interviews. Additionally, 6 children ages $7-12$ years old participated in photojournalism walks with accompanying open-ended interviews. Providing children with a variety of mediums to communicate their thoughts and ideas allowed for lengthy, complex discussions at a developmentally appropriate level. 
In this study, children raised concerns of feeling alienated and restricted by adults, both familial and not, in public space. Children also spoke of the ways in which they feel integrated and empowered by their communities and community members. Children in this study explained how they try to build community, and how they admire other's efforts to build community as well. I observed children's complex spatial awareness and savvy understanding of both real safety concerns and what Katz (2006) calls "terror talk" rhetoric (Katz, 2006; Valentine, 2004). I also investigated how children and adults differ in defining "the neighborhood." In this study, children viewed "the neighborhood" as a malleable social construction rather than a set of specific geographic boundaries. Most notably, children showed a deep dedication and emotional connection to each other and to their neighborhood at large.

This paper begins with a summary of relevant background literature, to provide context on children's rights and current ability to access public space. In that section I argue the need for further research on children's everyday use of neighborhood spaces. Next, I describe my research design and methodology. The paper then turns to research results. First I explore how the children in this study define "the neighborhood" and how age, personality, and a child's sense of autonomy influences the way they chose to depict and define their neighborhood. I go on to investigate how children participate in and also help to create a sense of community within the Arcadia* neighborhood. Next, I explore how children navigate public spaces within the neighborhood. Lastly, I investigate how children place value on public spaces.

I conclude by arguing that children are active community members who have the right to contribute to neighborhood decisions under The Bill of Rights for the Children and Youth of the

\footnotetext{
* Arcadia is a pseudonym for a Portland neighborhood. Portland State's Institutional Review Board required pseudonyms for both the participants and specific geographic locations in academic publishing.
} 
City of Portland and Multnomah County, which states that children have the right to voice their opinions on community matters (Our Bill of Rights: Children \& Youth, 2006) I also argue that children in this study are both capable of and have the desire to suggest changes to the Arcadia Neighborhood Association that promote social equity and community wellness in their neighborhood. I outline suggestions for better incorporating children's thoughtful, insightful feedback into neighborhood association meetings. I also highlight areas where further research is needed in order to develop a broad knowledge of children's everyday experiences of public space in urban neighborhoods. From this broad knowledge base I believe we can generate childfriendly neighborhoods, which will promote the rights of all residents.

\section{$\underline{\text { Literature Review }}$}

The lack of research and subsequent lack of child-focused urban planning policy regarding children's use of neighborhood spaces is in direct violation of the United Nations Convention on the Rights of the Child (CRC) and the Conference on Environment and Development (United Nations, 1992). According to UNICEF's broad interpretation of the Convention on the Rights of the Child, the environment of children's everyday lives is a critical aspect of fulfilling children's basic human rights (Chawla and Malone, 2003). Neighborhood environments must enable the rights of play and recreation, and the right to participate in the cultural life of the child's society. Everyday environments must also allow children freedom of association, the ability to seek and impart information and ideas through a variety of means, and to express their views in matters that affect them (CRC Articles 12, 13, 15, and 31; Chawla and Malone, 2003). As of January 2017 the United States is the only country that has failed to ratify the Convention on the Rights of the Child (Mehta, 2015). 
Children in the United States are increasingly losing their right to inhabit public space. Curfews and anti-loitering laws serve to criminalize teenagers' use of public space (Gammon, 2011). Parents who allow younger children to walk in public space without adult supervision can now face neglect charges, therefore disincentivizing parents to allow their children any sense of independence in outdoor public space (McCarren, 2015). This restriction of children's geographies means that children's free time and play are restricted to adult-monitored institutions such as schools and extra-curricular sports and arts activities. Restricting and institutionalizing children's play carries significant socioeconomic implications, with access to many of these activities being contingent upon parents ability to pay for their child's participation (Bradley and Corwyn, 2002). Children's rapidly decreasing access to public space must be critically examined. The current trends of criminalizing and stigmatizing youth's access to public space only serves to enforce social strata based on socioeconomic class and further subjugates children to the will of adults.

Seeing children as active social actors who both understand and are affected by social equity in their neighborhood public spaces is key to a child-rights and human rights centered approach. It is important to understand, and be responsive to, the wants and needs of children when designing urban public spaces, particularly in cities such as Portland that are experiencing rapid growth, displacement, and gentrification (Gibson, 2007). Public spaces in Portland neighborhoods can and should promote the rights of all residents, including children. Currently, we lack research that investigates how children access public spaces in their neighborhoods in the course of their daily lives (Bourke, 2016). In order to produce child-friendly urban planning policy we must first understand children's current relationship with the public spaces in their neighborhoods (Bourke, 2016). 
Well-meaning parents are often the primary barriers for children to negotiate in order to access open, flexible, and public play space. A significant body of literature ties the increase of parent anxieties to the rise in globalized and 24-hour news media stoking the fire of strangerdanger narratives, what Katz (2006) refers to as "terror talk" (Valentine, 2004; Villanueva et. al., 2014; Woolley and Griffin, 2014). The occurrence of this public discourse has the potential to distort local fears by heightening parents' awareness of the extreme and rare events of violent crimes committed against children, thus causing parents to restrict their children's movement in public space. Stranger-danger discourse also serves to keep children from intruding upon the adult-dominated public space (Valentine, 2004). This discourse is used as a means for controlling children, keeping them in the home and reducing their independence and autonomy.

Despite the "terror talk" and stranger-danger discourse, multiple studies have found that children are capable of safely navigating public spaces independently (Corsaro, 1997; Valentine, 2004; Woolley and Griffin, 2014). Research also shows that children are more at risk of harm in private spaces rather than public spaces (Corsaro, 1997; Valentine, 2004). Children are overwhelmingly harmed by familial adults on private property rather than by strangers in public space (Valentine, 2004). Most pedophiles abuse their own children, stepchildren, or children they otherwise have a familial relationship with (National Criminal Intelligence Service, 2002). Contrary to the popular myth of the lurking stranger, non-custodial parents perpetrate most child abductions (Spitzer, 1986). However, popular discourse continues to enforce the marginalization of youth in public space in the name of children's safety. I argue that in the United States we have successfully taught children to be hyper vigilant in public spaces while interacting with strangers and woefully unguarded while interacting with familiar adults in private or semiprivate spaces such as the home, schools, and organized sports programs. In order to counteract 
this marginalization of children from public space we must address children's inherent right to environments that enable their play, recreation, and ability to participate in the cultural life of their societies (United Nations, Article 31, 1992).

I argue that the first step in creating child-friendly environments is to understand how children currently interact with their everyday neighborhood spaces. Much of the research on children's use of public space comes out of Northern Europe and Australia. Many of these studies have focused on Children's Independent Mobility (CIM) rate (Mitra \& Raktim, 2014). CIM rate can be defined by "the freedom of children to travel around their own neighbourhood or city without adult supervision" (Tranter and Whitelegg, 1994). CIM rates are often based on parent and child surveys regarding the level of independence a child has in traveling to specific locations, such as school, the library, or play spaces. However, CIM rates are not measured on a consistent scale, and are therefore not comparable across varying social contexts. More recently, researchers have incorporated GPS monitoring and participatory GIS mapping in an effort to establish a standardized, comparable measure of CIM rates (Bhosale et al, 2017; Loebach and Gilliland, 2016; Schoeppe et al, 2016).

CIM rates offer researchers a quantitative understanding of individual children's independent geographies, but this measure fails to illuminate the social, political, and cultural aspects of constructing children's home ranges. CIM rates also inadequately captures children's perception of their neighborhood spaces, instead measuring if a child does or doesn't travel independently to a specific geographic location. An adult researcher, and not the children themselves, often selects these locations. This location selection process wholly ignores the locations and boundaries that are important to children but go unseen, or are considered to be unimportant by adults. CIM rate offers little insight into children's lived experiences of accessing 
public space due to adult bias in defining children's neighborhoods. By pre-defining spaces for children researchers take away children's role as active social actors who help to create and define community boundaries and important locations.

Bourke (2016) highlights the problems with measuring children's use of neighborhood space based off of their adult-like use of adult-specified spaces. Bourke argues that children see urban neighborhoods as, "a series of interwoven layers: social, sensory, pragmatic, and imaginative" (Bourke, 2016, p. 103). Bourke argues that children's flexible way of thinking allows for a creative use of public space. Bourke argues that children are an essential part of "citiness" and should be reclassified from passive consumers of adult culture to young urbanites, intertwined with an urban place, responsible for generating a sense of interconnectedness and synergy in their neighborhoods (Bourke, 2016; Seamon, 2012). Bourke calls for further research on the everyday lives and practices of urban children, arguing that in order to have robust cities we must acknowledge children as "co-constructors of dynamic public spaces and implement local government participative planning models that result in spaces which welcome their presence" (Bourke, 2016). This research aims to understand the everyday lives and practices of the children in the Arcadia neighborhood and position them as active social actors in the neighborhood community.

\section{$\underline{\text { Research Design }}$}

This qualitative study employs participatory action research methods to explore children's geographies of the Arcadia neighborhood. In the spirit of participatory action research methods, this study design was tailored to the interests and developmental capabilities of the subjects, children who are approximately 5 - 12 years old. Clark's (2004) Mosaic Approach 
brought together the tools of observation and interviewing with participatory tools to construct a composite picture or "mosaic" of children's lives. Clark's (2004) participatory tools are ageappropriate and include multi-media art projects, photojournalism projects, and informal childfriendly settings for interviews. Clark (2004) initially developed this research method for preschoolers. Stephenson (2009) implemented a photo-centered version with preschoolers as well. Woodson (2007) and Griffin, Lahman, and Opitz (2014) have conducted similar research with older children. Woodson's (2007) writing describes the validity of using teenager's artwork as data in sociological research. Griffin et al. (2014) detailed the usefulness of practicing "shoulder-to-shoulder" interviews with elementary school children. This interview style is informal and calls for the researcher to sit next to children while they, make art, or are otherwise going about their own business. Griffin et al. (2014) also described the success of the "walkaround" interview practice with elementary school children. This practice is a form of a mobile interview, where the children guide the researcher around the community (Griffin et al, 2014).

In this study, participatory tools for children consisted of two art projects. The first project consisted of child-made maps, depicting the emotional significance of place and space in the Arcadia neighborhood. The second project was a photojournalism and walk-around interview. This activity primarily consisted of small groups of children walking through the neighborhood with me and a disposable camera. The photos each child took captured their perspective of the neighborhood and places that matter to them.

All of the 21 child participants were self-selected members of the local community. Children were notified of this study via flyers posted in the neighborhood and by an email I sent to the Arcadia babysitting co-op (See Appendix A, Appendix B). The majority of the participants in this study were girls with a total of 15 girls and 6 boys. The majority of children in this study 
were White. Two children, both 5 years old, were Black. Three children, ages 5, 10, and 12 years old were mixed-race. Two children, ages 9 and 10 years old had parents who are Eastern European immigrants. The parents moved to the neighborhood approximately 15 years ago. The children and their parents spoke their native language and English fluently. The ages of the children were relatively well spread out, given the sampling method. 5-year-olds, 8 year-olds, and 12-year-olds had the highest representation, with approximately 4 or 5 children from each age bracket. 10-year-olds had the lowest representation, with only two 10-year-olds in this study. Children came from a variety of socioeconomic backgrounds, ranging from lower/working-class to upper middle-class, with the majority coming from middle-class backgrounds. The children's names, along with the names of the neighborhood itself, the local streets, and the local schools have been assigned pseudonyms or omitted in order to maintain the confidentiality of study participants.

\section{Positionality Statement}

My social statuses and pre-established relationships in this neighborhood enhanced my access to my sample population and also impacted the quality of data I obtained. While I do not live in Arcadia, I live close by. I had been a nanny for two children who live in Arcadia for 3 years prior to the start of this study. During my 3 years as a nanny in Arcadia I had come to know a handful of children and parents quite well. The two children in my care, a brother and a sister, are participants in this study. Their parents were serving as the chairs of the neighborhood co-op during the data-gathering portion of this study and assisted me in gaining the trust of neighborhood parents whom I didn't know personally. Using the co-op listserv, the parents I worked for sent out an email about my research goals and methods (see Appendix B). These parents also spoke directly to other adults about my trustworthiness when it came to the safety 
and consideration of children. While I relied heavily on my connections with the adults in Arcadia to gain validation and trust from other adults, I was extremely cautious about accessing my pre-established relationships with the children. When speaking with children about participating in this study I made a point to say that they should only do the projects if it seemed like it was fun. I also told the children that I wouldn't be mad, sad, or upset with them if they chose to not participate or to stop participating.

My status as a white female college student also influenced my access to and relationship with the participants in this study. In particular, my age and gender combined with my stated research purposes enabled me to have relatively unfiltered access to the child participants. For example, parents who I didn't know trusted me to be alone at the library with their children or would allow me to take their child in a small group on a photo walk where I was the only adult present. I was old enough to be taken seriously by adults, yet young enough to be trusted as a not-adult by the children. One child I knew prior to this study discussed this phenomenon:

Emily, age 6: "Well you see, you're not really a kid-kid because you're bigger and you're twenty but you're not a grown-up because you're not a mom and you still have homework and go to school. My mom says you're a young adult. I think you're a babysitter which is kind of like a kid but not."

Being, "kind of like a kid but not" felt crucial to the honesty and quality of the discussions I had with the participants in this study. I managed to exist in a grey area where I was trusted and taken seriously, but I also wasn't an authority figure or anyone of any particular consequence. Straddling the kid and adult worlds opened a unique opportunity for research and data collection in this case study. Randall's (2012) research methodology advocates for this "least adult role" as a way of establishing a trusting and open relationship with child participants. 


\section{Study Area}

This case study takes place in the Arcadia neighborhood in Portland, Oregon. This innernortheast neighborhood is old and established. There are fully paved roads, walkways, and bike streets called "Greenways." There is easy access by car, bike, or bus into downtown and easy access by car to the major employment centers of Intel and Nike, which are in the nearby suburbs. This neighborhood is home to a natural foods grocery store, a public library branch, multiple coffee shops and cafes, and various small businesses including a children's bookstore. The neighborhood public school offers the IB (International Baccalaureate) program to it's K- ${ }^{\text {th }}$ grade students in addition to providing on-campus school gardens and a newly remodeled "nature playground." The houses are colorful craftsman style homes with bungalow style intermixed along the streets. Established trees arch over the side streets, with a few open to the public rope swings strung up by friendly neighbors. Down any given street there could be an old Subaru parked in front of a new Range Rover. In late 2016, with the rise of the Black Lives Matter movement and the election of Donald Trump, many front yards host "Black Lives Matter" and "All Are Welcome" signs. The neighborhood families are tightly knit. They have created a babysitting co-op (an email listserv where neighborhood parents can exchange earned "points" for babysitting with other neighborhood parents) and throw neighborhood parties during the summer months.

According to the 2010 U.S. Census, this geographically small neighborhood has an approximate population of 4,000 residents. The majority of residents, $56 \%$, live in family households. The median age in the neighborhood is 37 years old. About $20 \%$ of the neighborhood population is under the age of 18 , with $10.2 \%$ of the population ranging in age from 5 - 14 years old. The gender division among the child population of Arcadia is almost evenly split, with 207 boys and 219 girls, ages $5-14$ years old. In the last 10 years, the Arcadia 
neighborhood has seen a significant shift in the racial composition of the neighborhood without a significant shift in the total number of residents. This neighborhood saw an uptick in the number of white residents, rising from approximately $60 \%$ white in 2000 to $80 \%$ white in 2010 .

Corresponding with this trend, there was an almost 50\% decrease in the African American population of Arcadia over the last 10 years, a trend that is consistent across several Portland neighborhoods. Additionally, there was an approximate $20 \%$ drop in Latino residents during the same time period. This change in racial demographics reflects the change in the housing market and socioeconomic situation of Portland, Oregon.

The Arcadia neighborhood is a sub-section of Portland's Albina District. After a series of deliberate choices made by the City of Portland government and local banks, the Albina District became Portland's “Black Belt" or "ghetto" from the 1940's through 2000 (Gibson, 2007). Gibson's (2007) case study, Bleeding Albina documents the segregation, predatory lending practices, and the disinvestment of public services and infrastructure that led to Portland's Black residents being trapped in slum-like conditions in the Albina District. Four elementary schools, one of which is in the Arcadia neighborhood, were more than 90 percent Black during this period despite Black residents making up only 6 percent of Portland's overall population (Gibson, 2007). Starting in the early 2000s young White residents returned to the Albina District, empowered by business and home loans and grants that had historically been denied to Albina's Black residents (Gibson, 2007). Arcadia's racial profile has continued to shift since Gibson’s 2007 case study. Wealthier, White homebuyers have displaced Black and Latino residents. The elementary school in Arcadia that was once overwhelmingly Black is now predominately White, with Black students making up approximately 15 percent of the student population. This is one of the lowest percentages of Black students in any public elementary school in the Albina 
District (National Center for Education Statistics; Oregon Department of Education).

\section{Mapmaking}

A total of 19 children drew maps of their communities while participating in open-ended, focus group style interviews. This mapmaking activity was held at the neighborhood public library on three separate afternoons in late September 2016. Participation was completely optional and didn't impact children's ability to access the library. I set up an art table for 2 hours on 3 separate days in the children's section of the library. Two of these times occurred after school on weekdays, and one slot occurred on the weekend. I provided the art supplies for the map-making activity, which included blank white paper, washable markers, and crayons. The local library provided physical space along with tables and chairs.

I sat at the table and asked any children who appeared to be both in the desired age range and interested in the art supplies, "Would you like to draw a map of your neighborhood for my school project?" The children's librarian would also approach children she knew well about possibly participating in the map-making activity. If the child nodded their head yes or otherwise verbalized their consent, I would go on to explain the purpose of the project, ask if it was okay to take a picture of the child's completed map without their name on it, and informed the child that I was recording their voices to help me remember what the child was saying. If the child was no longer interested, I would smile and say "I understand, thanks for listening to me tell you about it!" If the child maintained their consent I offered markers, crayons, and paper. I started a conversation about what the child was including in their drawing. When the child finished drawing their map I spent approximately 10 minutes discussing the map with the child, focusing on what the child included in their drawing, why the child included certain people or places, how those places made them feel, or what those places made them think of. At any given time one to 
four children were working on a map and discussing their artwork with myself and with each other. This led to both lively conversations between the children about the maps, and also created in-depth one-on-one conversations between individual children and me.

To determine if a child was a resident of the Arcadia neighborhood I asked, "Does this library, the place we are now, feel like part of your neighborhood?" If the child said yes, and also discussed local aspects of the Arcadia neighborhood, that child was considered a resident for the purposes of this study. Obtaining actual home address data and comparing it with city maps of the neighborhood boundary posed an excessive burden on the participants and also posed a significant privacy issue. If the child declared they were not a resident but they still wanted to draw a map, they were allowed to participate, but their map and interview was not included in the data set. This approach prevented young children from feeling excluded from an activity that took place in public space.

\section{Photojournalism \& Walk-Around Interviews}

The second project was a photojournalism and walk-around interview project. Bourke's (2016) study employed photography and photo-elicited interviews with children ages $9-11$ years old in Dublin City, Ireland. Bourke argues that the photography portion of Clark's (2004) Mosaic Approach "reflects an understanding of children as agents shaping their own social life experiences." This activity primarily consisted of small groups of children walking through the neighborhood with a disposable camera and showing me their favorite places, places they disliked, and/or places they wished to change. The photos each child took captured their perspective of the neighborhood, allowing each child to show the places that matter to them. I provided the cameras for each child and returned the hardcopy prints to each child once data 
analysis was complete. I kept scans of the photographs for my reference. Interviews were digitally recorded, transcribed verbatim, and coded for reoccurring themes.

Children's guardians were notified about the photojournalism project via an email to the neighborhood babysitting co-op (see Appendix B). I also personally informed 3 children about the photojournalism walks after they had completed the map-making activity at the local library. I chose to inform these children directly because they each spent over an hour on their map and expressed a great deal of interest in participating in this research. All 3 children chose to participate. In total, 6 children (5 girls and one boy) participated in the photojournalism project, 4 of whom also made maps.

Once children and their guardian(s) consented to participating in the photojournalism project and walk-around interview, I scheduled one-hour blocks to do the project with small groups of participants. I asked the guardians to select a meeting place, and all chose to have me arrive at their homes and pick up the children. I had three groups for the walk-around interviews. The first consisted of a new Arcadia resident, age 7, who requested to have her mother come with us. The mother was familiar with the academic research processes and took great care to create a comfortable environment for her child without overtly influencing the child's responses. The second group consisted of three girls, ages $8-12$ years old. Two were sisters, and the other was a close friend of theirs. Again, one child in this group requested that her father join us. He followed behind us for approximately 15 minutes, and once the girls seemed to be more comfortable he departed, leaving me with the three girls. My last group was a pair of siblings, ages 10 and 9 years old, and myself. I had an established relationship with this brother and sister prior to this study, so it was unsurprising that neither of them requested a parent to accompany us. 
All three groups needed a tutorial on how to work a film camera and quickly picked up the mechanics of it. Some children were wary to take photos because they couldn't delete any photos off of the camera, making it challenging for them to allocate their 27 photos across the neighborhood. In one case this resulted in the photojournalism aspect dropping by the wayside and the walk-around interview becoming the primary focus. In another instance, two children ran out of film and proceeded to verbally tell me "photo of that!" if we passed something they wished they could take a picture of.

\section{Participant Observation}

In addition to the data collected from children's artwork and interviews this case study is also informed by detailed field notes from approximately 30 hours of participant observation of children's behavior and use of public space in Arcadia. I conducted participant observation in the months of August through March at organized public events at the Library and in public gathering spaces, specifically the neighborhood shopping center and public parks. The primary source of participant observation field notes came from the January 2017 "snowpocalypse." The city of Portland experienced unusually heavy snowfall for the region, followed by an ice storm, causing the public schools to shut down for a total of 9 school days in the month of January. This meant that children were out and accessing the neighborhood en mass during daytime hours. I chose to observe activity at the top of "Mount Doom," a particularly steep street that the local children blocked off and used as a sledding hill during the "snowpocalypse."

\section{Data Analysis}

I used qualitative content analysis to analyze data in this research. "Content analysis is a research method used to analyze social life by interpreting words and images from documents, film, art, music, and other cultural products and media" (Crossman, 2016). As stated above, both 
activities were treated as focus-group style interviews. I made audio recordings of the mapmaking activities and the walk-around interviews. These recordings were transcribed verbatim and coded for reoccurring themes in the children's discussions about Arcadia. Children's maps and photos were analyzed for repetitious physical locations, weather notations, symbols of daily activities, and other people. Interview transcripts were analyzed for children's discussions pertaining to the following: defining their neighborhood, how they participate in and make community, feelings of autonomy and safety, and how they construct value for physical neighborhood locations.

This data reshaped my research questions in two ways. First, I found that children had strong attachments to their definition of the neighborhoods. I changed my research question from "How do children see public space in urban neighborhoods?" to "How do children define public spaces in urban neighborhoods?" in order to further validate and legitimize children's definition

of the public spaces. Secondly, I noted strong themes of social involvement and social awareness in this research. I re-conceptualized the idea of how children "use" public spaces and opted instead to investigate how children participate in, and make community within, their neighborhood.

\section{Findings and Discussion}

In this study I found that children have a complex understanding of community, public space, and "the neighborhood." A child's age, personality, and sense of autonomy largely influenced the scale and scope of their individual neighborhood geography. Children raised concerns of feeling alienated and restricted by adults, both familial and not, in public space. Children also spoke of the ways in which they feel integrated and empowered by their 
communities and community members; how the children themselves try to build community, and how they admire other's efforts to build community. Children demonstrated their complex spatial awareness and savvy understanding of both real safety concerns and other "terror talk" rhetoric. Most notably, children consistently communicated a deep dedication and emotional connection to each other and to their neighborhood at large. The children in this study value their neighborhood in a socio-spatial context, meaning that they form social and emotional relationships in their built environment. Children convey that the relationships formed and maintained in public space give them a sense of ownership and pride over those public spaces in the neighborhood. Children also offered suggestions for improvements based on a belief that their neighborhood can and should continue to improve for the good of all its residents.

\section{Defining "The Neighborhood"}

Children's definition of the neighborhood is influenced by many factors and is different from the way adults define a neighborhood. Adults" definition of "the neighborhood" is rigid and prescribed. I observed that adults in Arcadia will cite map boundaries designated by the city when asked to define their neighborhood. In contrast, children's definition of the neighborhood is flexible and evolving. Children's conceptualization of "the neighborhood" is socio-spatial. Children define geographic spaces by the social relationships fostered in those spaces. These relationships and physical spaces are nested within the context of an individual child's age, personality, and personal sense of autonomy to create the ethos of "the neighborhood."

Hannah, age 12: My neighborhood is the hill where I live on. I just really like that neighborhood. My school is by there. I have really nice neighbors. When it's a snowy day, we go, everybody in the neighborhood, around all of here, would go onto the hill and sled down it. It's really fun.

Silvie, age 9: Sometimes I feel like the only place in [the state] is my block. I don't know why. 
Emily, age 6: I can draw my neighborhood and that is just my house.

A child's age is a key aspect in shaping the scale of the neighborhood. Younger children, ages 5 -7 years old, generally depict their neighborhood as their family's house. Younger children's maps will often include part of a yard, a special tree, the weather, the front sidewalk, and sometimes will include part of a driveway. Young children depicted mostly private spaces. While all children in this study think of "the neighborhood" as connected areas where social attachments are formed and maintained, younger children in particular focus on the most intimate social connections of their childhood: the family unit. Older children, ages $8-12$ years old, generally included broader geographic areas in their maps of the neighborhood. Older children's maps typically included labeled streets, their house in relation to friends' houses, the local library and nearby businesses, and sometimes the public elementary school. There are exceptions to these generalizations, and age intersects with two other factors that are also important in determining the scale of a child's neighborhood: personality and sense of autonomy.
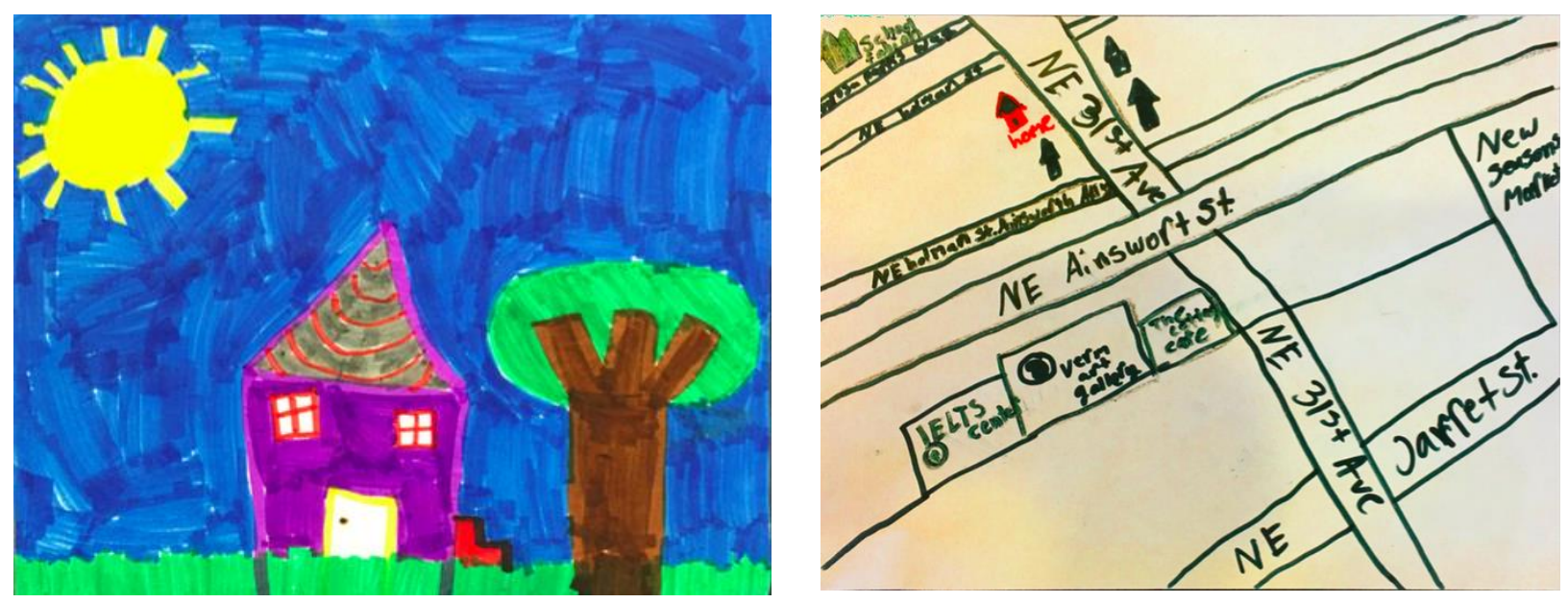

Typical Map for $5-7$ year olds

Map by: Audrey, age 6
Typical Map for 8 - 12 year olds

Map by: Madison, age 12 
A child's personality, specifically how introverted or extroverted a particular child is, ties to the scale of the neighborhood. This was most apparent with older children, who generally had more geographic locations they could travel to without direct adult supervision than younger children. Older children who demonstrated more dominant personalities in focus group discussions, expressed interest in large group social or sporting activities, and had parent permission to roam the neighborhood, discussed particularly large neighborhood ranges. In contrast, older children who demonstrated quieter personalities and expressed interest in small group or individual activities had smaller than average neighborhood ranges, despite having similar parent sanctioned boundaries for roaming the neighborhood. For example, one particularly soft-spoken 12-year-old was the only older child to draw just her house for her neighborhood map. The house was drawn with great detail, each plant in her front yard was individually depicted and the child's bedroom window was highlighted in the drawing. In contrast, one very outspoken 9-year-old girl gleefully described her neighborhood as the entire city of Portland and recounted her mother's cautious willingness to let her cross busy streets by herself to get to the district high school's recreational facilities:

Silvie, age 9: There it's busy. Because then my mom, literally, when I get back she's screaming with joy, I'm not dead yet.

Both children in the examples above had similar parent sanctioned neighborhood boundaries. I also observed both girls traveling through the neighborhood streets with a friend, unaccompanied by an adult, on numerous occasions. In this case the different personalities of the children helps bring context to why an outgoing 9-year-old's neighborhood can be so much larger than a quiet 12-year-old's neighborhood.

A child's personal sense of autonomy is the third factor that impacts the scale of the neighborhood for young children. Children value spaces where they feel they can be self-directed 
and are either totally unsupervised, or at least indirectly supervised, by adults. For younger children, ages $5-7$ years old, avoiding adult supervision is almost impossible outside of the home. No child in this study between the ages of $5-7$ years old expressed any ability to independently travel somewhere in the neighborhood, or travel somewhere locally while in the company of an older sibling. This helps explain why young children will draw their family homes with great detail while placing little significance on any other part of their neighborhood. For example, 6-year-old Emily insisted that her neighborhood, "is just my house" despite gentle prompting from her father to include the local library and nearby shops on her map.

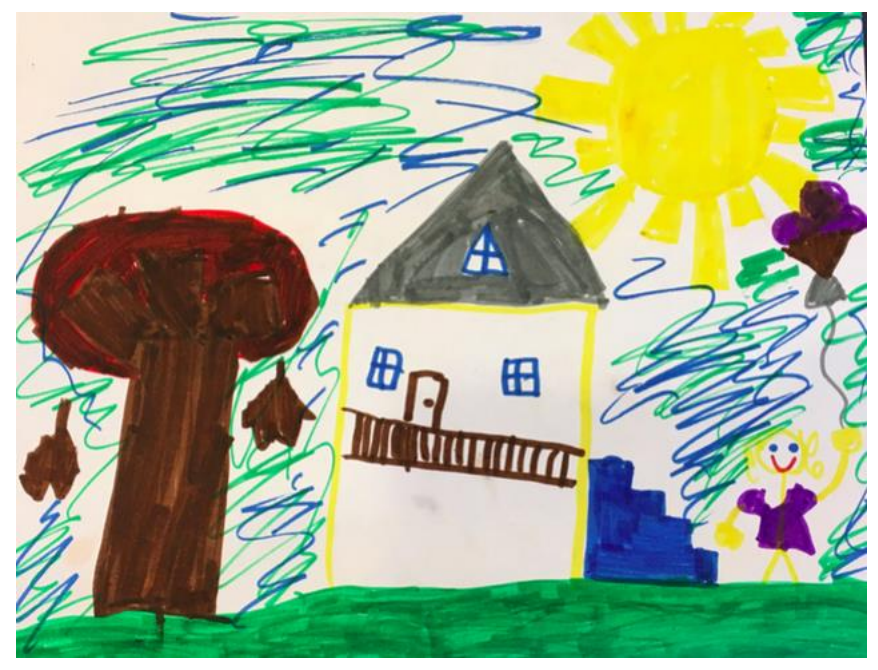

Map By: Emily, age 6

Emily's map shows the locations where she is allowed the least amount of adult supervision in her day. She is allowed to play in her family's front and back yards without an adult directly watching her, and she is also allowed to play on the front porch without adult supervision. In her interview Emily repeatedly told me that she, "gotta draw the back steps, oh yes!" The back steps enable her to access both yards and the family driveway, making them an important aspect of her neighborhood. In her drawing the steps are large and colored in with her favorite color, emphasizing the importance of the steps. 
7-year-old Liam's definition of “the neighborhood” was similar to Emily's. Liam also drew his house in great detail, placing emphasis on the front sidewalk, his family's driveway, and the street in front of their house. Liam enjoyed riding his bike, but only in close proximity to family property, and included this activity on his map. Liam's little brother Jacob, who is 6 years old and also participated in this study, doesn't ride his bike or play in the street without an adult present, however Jacob has fairly unrestricted access to the driveway and sidewalk in front of his family's home. Liam shares Jacob's unrestricted access to family property and additionally is able to access part of the street in front of their house. Liam's age and subsequent larger geographic range of indirectly adult supervised space gives him a slightly larger definition of the neighborhood when compared to his younger brother.

Researcher: Can you tell me about what you drew?

Liam, age 7: My house, and me riding and Jacob's bike and me riding bikes across the street.

Researcher: Cool. Is it important for you to be able to ride your bike? Do you ride in the street or do you ride on the sidewalk?

Liam: (Liam nods his head yes) Both.

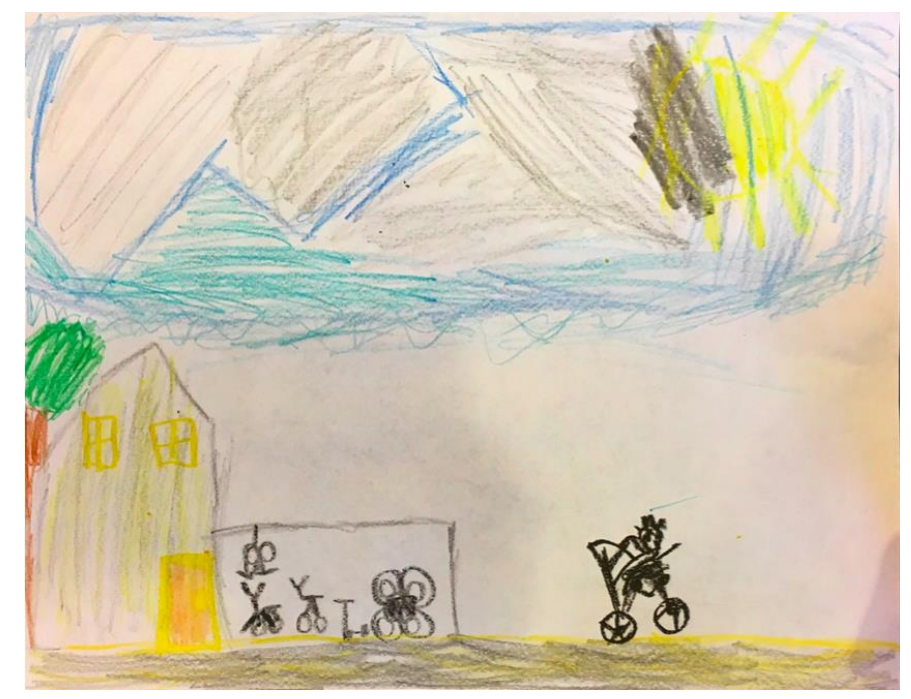

Map by Liam, age 7 
Older children also seek spaces that are separate from adult spaces. I observed that children ages $8-10$ years old actively sought to create spaces that disrupted adults' ability to supervise them. This is in contrast to children ages $5-7$ years old, who valued spaces where adults indirectly supervised them. The younger children didn't attempt to disrupt and avoid adults being in children's spaces, where older children do actively attempt to make spaces that adults cannot access or supervise very easily. For example, 8-year-old James claimed a dirt patch under a tree as an area that is, "mine. It's where me and my friends would hang out at recess because the teachers can't really see us." One 10-year-old girl constructed a "special fort" in her backyard that is exclusively for children in the neighborhood to play in. I watched her haul herself and her camera over an 8-foot fence to document her fort as part of her photojournalism walk.

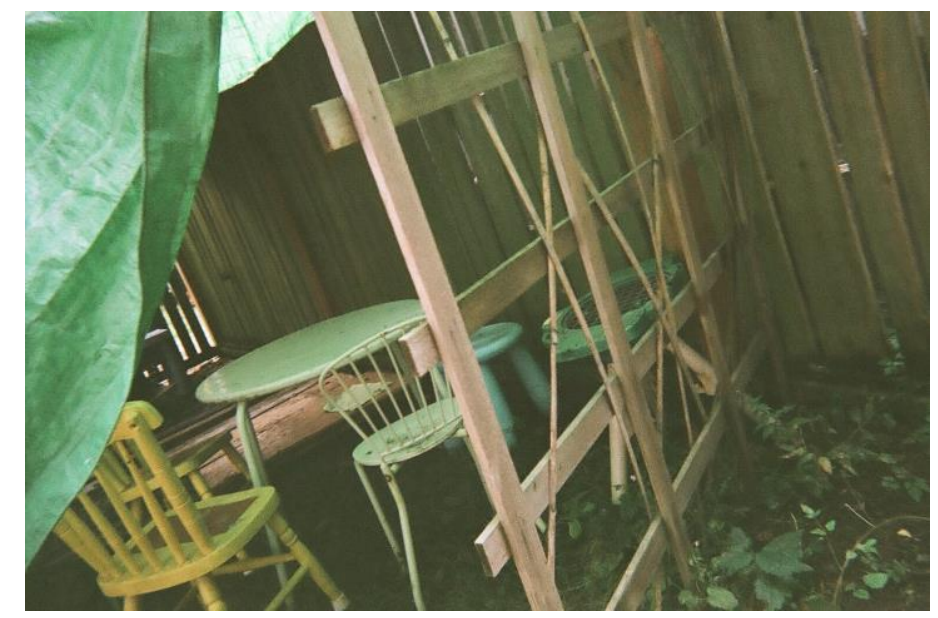

Special Fort. Photo By: Hailey, age 10

The oldest children in this study, children ages 11 and 12 years old, sought out a sense of autonomy differently than children ages $5-10$ years old do. Children on the cusp of their teen years expressed interest in navigating adult-dominated spaces independently or with their peers without any adult supervision. Unlike children ages $8-10$ years old, the preteens in this study did not attempt to make themselves inaccessible to adult community members. Instead, the 
preteens attempted to portray themselves as adult-like and access adult spaces such as the coffee shop and the library without a parent present. This social showmanship appeared to be an attempt by the children to show their community that, as almost teenagers, they are competent and capable of navigating the adult world. Children ages 11 and 12 had larger geographic ranges in their definitions of the neighborhood because these older children have a larger autonomous range in their everyday geographies than younger children do.

For example, Hannah and Madison, both 12-year-olds, discussed liking the ability to go to the local coffee shop now that they could go together without adult supervision. Hannah also emphatically declared the library to be her favorite place. Hannah lit up when discussing her love of reading. She also jumped at the chance to differentiate herself from the coffee-shop-girls, telling me that while everyone else goes to the coffee shop she chooses to go to the library alone.

Hannah, age 12: "I love going to the library. I love to read. I just like all the stories that come from the library. If it wasn't here, I would be so sad. I would have nothing to do. I could hang out with friends, or I'd just be crowded on my phone and then I wouldn't actually be doing something. That's fun but I like just hanging out at the library and reading."

I observed Hannah with the other girls at the coffee shop on multiple occasions. It was clear to me that Hannah enjoys being out in her community. I also observed that she values the ability to make these connections on her own terms. For Hannah, the library means that she can be around people without having to directly interact with them. After a long day at school this type of socializing with her community is a welcome combination of solitude and company. Hannah and Madison both access neighborhood spaces when they wish to be seen by their community as competent, equal members of the neighborhood.

With the layered context of children's age, personality, and sense of autonomy explaining the variation in the scale of children's geographies, one unifying theme emerged in all of the 
children's definitions of "the neighborhood." All of the children in this study defined their neighborhood in a socio-spatial framework, meaning that all of the children reported their geographies to be based on their social relationships that are fostered in and among different neighborhood spaces. Two primary social relationships fostered in neighborhood spaces are the parent-child relationship and the child's peer relationships.

The parent-child relationship is of particular importance to children in this study when it comes to assigning positive feelings to public space in the neighborhood. Children who spend more time in a variety of public spaces with their parent draw larger and more detailed neighborhood geographies at younger ages when compared to their peers. Young children, ages $5-7$ years old, who walk or take the bus regularly with their parent(s) depicted more important locations on their maps than their peers who are primarily transported in cars. Importantly, of the three younger children in this study who primarily walk or take the bus, two of them were also the only Black participants. These two children both lived in a low-income housing project at the edge of the Arcadia neighborhood. Their families couldn’t afford bicycles for the children, nor did either family own a car. This is in contrast to the third young child whose family did own a car and bicycles. This White family placed a high value on environmentally conscious behaviors and opted to take the bus and walk as often as was relatively convenient for them. Given the central location of the family's rental house in the neighborhood, this family could easily walk to a number of local businesses and access a major public bus route.

Across socioeconomic boundaries, riding the bus with a parent is an important activity to children. The bus moves slowly and brief walks are often involved, making it easy for children to safely and calmly observe the space around them. Once on the bus, children are comfortable and are able to interact with their parents without their parents being distracted by the road. As 
children grow up, the bus becomes less relevant in their lives if the family can afford car-based transportation, much to the children's disappointment. Two older girls wistfully recounted riding the bus every day with their dad when he took them to preschool, a routine that ended once the girls began attending the neighborhood elementary school. Bus commuting provided important space for child and caregiver bonding time while also allowing a child to gain a broader sense of public spaces.

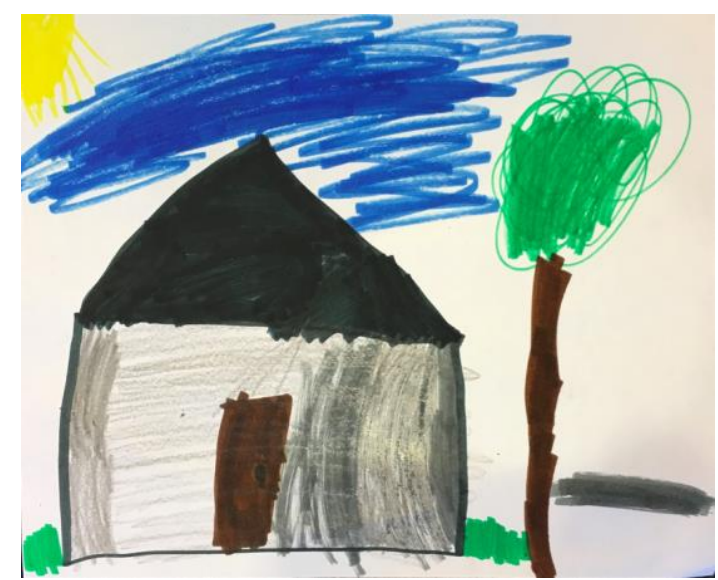

Primarily car and bike commuter Map By: Jacob, age 6

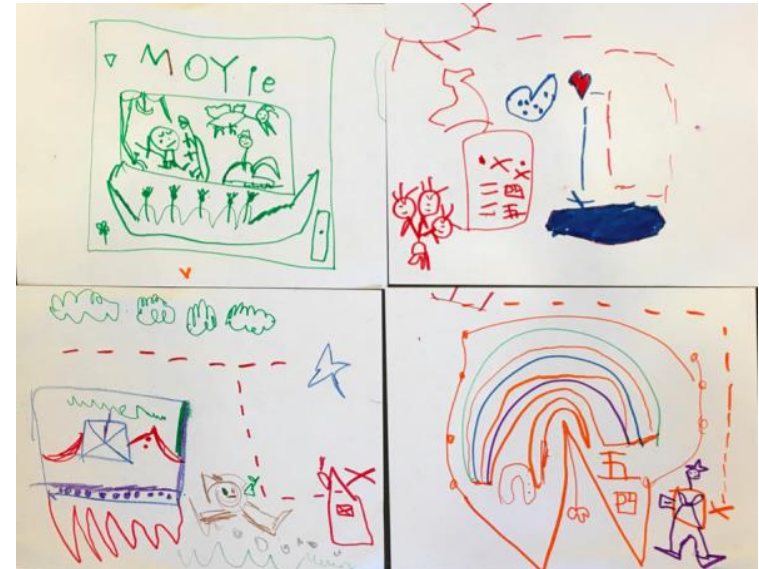

Primarily walking and bus commuter Map By: Caleb, age 5

Surprisingly, bike riding was not associated with a broader geographic range for the children in this study. Even when a parent, who chose to stay for the mapping activity, was vocal about valuing bike riding as a way of accessing the neighborhood the child declined to include bike riding on her map. Children under the age of 10 only spoke positively about riding their bikes on or very close to family property. Bike commuting was generally regarded by younger children as an unpleasant experience. Children disliked the chorus of "be careful!" that accompanied riding their bike to neighborhood destinations like the library or the school. Children also reported the ride home to be exhausting and hot. Bike commuting was the only 
parent-initiated bonding activity that young children quietly expressed a dislike for. However it is important to note that recreationally riding bikes near the home with parents and siblings is highly valued by young children. Neighborhood design may play a role in young children disliking bike commuting. This neighborhood has narrow two-way streets that can be dangerous even for adults, who are easier to see. This neighborhood is also situated on a relatively steep hill that can be challenging even for fit adult riders to summit on a bike.

Children's peer relationships also impact their definition of the neighborhood. Starting around age 8 , children began placing their house in relationship to friend's houses on their neighborhood maps. Children of all ages spoke of friend's houses and other locations embedded in their child-lore as extremely important places. Billy Gryphen's house was one such geographic marker. This mysterious site of child-lore is notorious with the Arcadia neighborhood children and served as a landmark for numerous project participants. For example 8-year-old James asked, "Do we turn on Billy Gryphen's street?" when asking about a route. The notoriety of the house seemed disconnected from any adult-oriented rationale, however, and even the children were unable to explain what specifically made Billy Gryphen's house important. Nonetheless, it occupied a larger than life role in the children's geographies of the Arcadia neighborhood. Across age groups in this study, children labeled knowing other children and forming social bonds with them as the most important aspects of making a neighborhood "good." During an interview with two 6-year-old girls, Audrey and Emily, Audrey talked about how living close to her best friend Emily and knowing other kids mattered to her more than knowing adults or having access to local shops.

Researcher: How do feel about there being a lot of buildings nearby? Do you care at all? Do you like it? Do you not like it?

Audrey, age 6: I don't care. 
Researcher: You don't care, yeah. What are other things that you do care about, that are fun to have close by?

Audrey: Neighbors.

Researcher: Neighbors, so you like having people that you know?

Audrey: Emily!

Researcher: (laughs) Is there anything else? Are there adults that are your neighbors that you like to know?

Audrey: Kids. Everybody likes kids. They're very fun.

The evidence above demonstrates that children's definition of "the neighborhood" is impacted by a number of factors and changes over time. Children define the neighborhood in a highly individual, emotionally intimate way. A child's age, personality, and sense of autonomy impacts, and is also impacted by, the social relationships formed and maintained in

neighborhood spaces. A young child with an outgoing personality, a wide scope of parent sanctioned unsupervised travel, who largely walks or takes the bus has a very different understanding of the neighborhood than a child who is older with a quieter personality who generally travels in a family vehicle. Children appear to sense the flexibility of their understanding of the neighborhood is different from the rigid definition of the adults' neighborhood. Children are also confident when expressing their view of the neighborhood, even when well-meaning adults attempt to "correct" children's definition of the neighborhood. Children want to be taken seriously as active neighborhood community members and want their definition of the neighborhood to be seen as equal and valid too.

\section{Participating In and Making Community}

Children help to create and also participate in Arcadia's neighborhood community. Children in this study felt motivated to be active community members. This sets the stage for safer and healthier communities as these young residents continue to grow (Chawla and Malone, 
2003). Public spaces in the neighborhood that are sites where children practice making their own child community or participate in the adult community are of particular importance to them. Spaces that allow children free, relatively unsupervised play are key for the creation of a robust child culture and community (Corsaro, 1997; Valentine, 2004). When the children who I interacted with during my data collection feel that there are spaces in the community for them, they value the neighborhood as a whole and try to give back to the community at large through active social participation. This giving back manifests as children carefully reading lost animal signs and looking for the lost pets, taking care of and valuing community gardens, and verbally praising what they see as adults" attempts at cultivating "cool" and "pretty" playgrounds, sitting spaces, and pieces of public art.

Children in Arcadia create their own peer culture in addition to participating in the adult culture of the neighborhood. Peer culture is an observable, separate culture that children cultivate amongst themselves through child-lore, a stable set of activities or routines, artifacts, values, and concerns (Corsaro, 1997; Opie, 1959; Thorne, 1993; Valentine, 2004). One example of this unique peer culture is the language used by the local children to name important places. "Mount Doom" and "Mount Terror" border the local school on the west and east sides, respectively. Mount Doom and Mount Terror are each made up of approximately $3-4$ city blocks that are unusually steep for the neighborhood. Mount Doom is widely loathed by the children who either must or choose to ride their bikes up or down it. Most children opt to walk their bikes in either direction, though a handful of adored and skillful pre-teens manage to gain enough momentum to ride up, and maintain enough control to avoid crashing on the fast ride down. On the few days of the year that the city of Portland gets snow the local children coopt Mount Terror from car traffic and use it as a sledding and hang out area. By using stolen traffic cones and sheer numbers the 
children are able to maintain the entire street as their own as long as there is snow on the ground. Mount Doom and Mount Terror are named and claimed by the local children because they are influential landmarks in their day-to-day lives. They are places where one demonstrates bravery and physical strength to peers. These streets are also largely unmonitored by adults, making them important sites of kids-only space.

Most public spaces that have been renamed by the neighborhood children are places where the children have an increased level of independence from adults. The main business center is called "the library district" because the library is one of the few places in the business center that is fully responsive to children. The library is also one of the first places that many children are allowed to explore without a parent next to them outside of the family property. It is free to access, many children have established relationships with the librarians, and it is open during the times that children are likely to be able to access it: after school and on the weekends.

Small parks are also highly valued by children in Arcadia. Like the library, smaller parks are accessible to children without an adult present. Arcadia hosts three parks, the largest is Butler Park which boasts two basketball courts, two baseball fields, a playground, a water playground, a tennis court, an off-leash dog area, and tree-lined walking paths. The mid-sized park is actually the public school grounds, which opens as a public park during non-school hours. The final park is the smallest. Tucked between two single-family homes, Two Petal Park takes up only one city lot. With a small playground, a single bench, and an enchanting collection of bushes and trees, this park is adored by the children of Arcadia. 


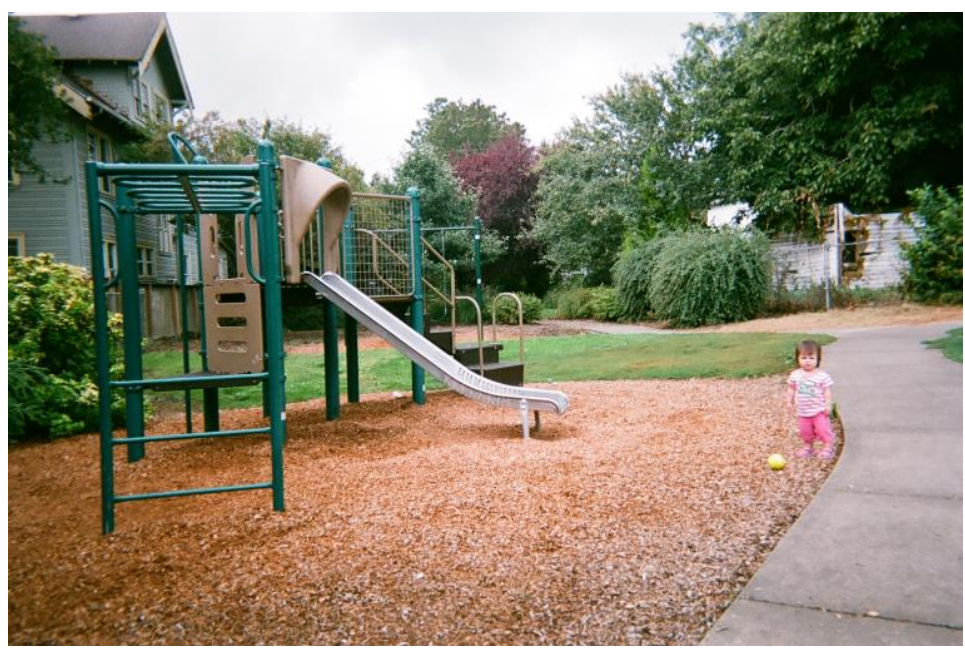

Two Petal Park. Photo By: Hailey, age 10.

Two Petal Park is special to the neighborhood children because it is small enough for them to be able to claim the space as theirs. Children told me that they can see who is coming and going from the park, making them feel safe. I observed that few adults or teenagers are attracted to the park, leaving Two Petal for the younger residents of Arcadia. This park is a meeting place for children. The safe yet almost adult-free space allows children to cultivate friendships and play in make-believe worlds of their own. The fact that it is simply a house lot converted to a park means that traveling to the park is easy for most residents. Children can take quiet side streets to the park, making this park and the library important sites of child culture, community, and independence.

Children spoke of connecting to their communities in a variety of ways. For younger children (ages 5 -7), knowing other kids was of particular importance when it came to creating a sense of community. For older children (ages 8 -12) knowing all community members, including adults, marked a sense of being integrated into the community and a sense of safety. Having established connections with members of the community also correlated with children remarking that their neighborhood was a safe or a good place to live. 
Abigail, age 9: I just like the neighborhood, in general. It's a nice neighborhood.

Researcher: Does it feel safe to walk around in?

Abigail: Yeah, definitely.

Researcher: What do you think makes it feel safe?

Abigail: Well, there's a lot of neighbors. Every Christmas, my mom and a few of the other neighbors put on this thing, where we all meet in one house, and have one course of dinner or something. Then, go to a different house to have maybe, the main meal or something like that, every Christmas. One house, it's like the "hang out" house, like a little school with different rooms you go to. More like a street. I like all the neighbors. They're very nice.

Researcher: What are other things that you do care about, that are fun to have close by? Audrey, age 6: Neighbors.

Connecting with neighbors is a key factor in a child identifying their neighborhood as "good" or "safe." For younger children, ages $5-7$ years old, this connection is primarily centered on their peers, while older children ages $8-12$ cite connections to non-familial adults as the primary source of goodness in the neighborhood. More than specific businesses, parks, or play spaces, children discussed their familiarity with the people who live on their street, their friendship with the librarians, and being identified as a "regular" by the neighborhood baristas as their favorite parts of Arcadia. Feeling like peers and adults see them as members of the community is important to children. Arcadia meets this need of the local children quite well. The neighborhood culture of summer block parties, babysitting co-ops, and a strong neighborhood association cultivates a palpable sense of community for both children and adults.

Children also quickly pointed to where Arcadia falls short when creating a socially equitable community. Issues of poverty and homelessness came up in a number of my conversations with the children of Arcadia. Arcadia's borders are peppered with non-profit social services, but in the core of the neighborhood there is a noticeable lack of organizations and 
services to meet the needs of the poor. It is not uncommon to see a lone man in raggedy clothes pushing a shopping cart up the street, searching for tin cans or glass bottles. The contrast between these presumably houseless men and the picturesque homes lining the street is stark. Children grappled with mixed feelings of fear and a strong sense of empathy towards these individuals:

Silvie, age 9: "I know some people are homeless. They can be dirty and sometimes they've got scratches all over them. I don't blame them, but it scares me sometimes.

Vasek, age 10: "I think there should be a homeless shelter here. I think there is a place downtown. There should be a place where homeless people can go and rest."

Silvie: "They do deserve to be here. They don't deserve to be homeless, but they do deserve to be here, actually."

These quotes demonstrate children's desire to be a part of socially equitable communities. They are able to identify injustices in their own neighborhood, such as the lack of services to people who are houseless. Children in Arcadia believe their community can and should do better when addressing these issues of social equality.

Children also noticed "not fair" city design with the neighborhood sidewalks. Hailey, a 10-year-old who had used crutches for a month prior to this study, advocated for more accessible street and sidewalk design. She noted that accessible neighborhood design benefits a wide range of residents such as, "people in wheelchairs, people with bicycles, or strollers." As an otherwise able-bodied child, Hailey doesn't currently need handicap accessible sidewalks. However she empathetically advocates for the needs of strangers in her neighborhood. This again demonstrates children's desire for socially equitable communities that truly serve residents across socioeconomic and ability statuses. This is also evidence for children's ability to interpret and care about the needs of others within their neighborhood. Children know that when a community is fair and socially just it is a better community overall. 
Children use public space in the Arcadia neighborhood to create and participate in their communities. They use their neighborhood to cultivate their own social skills and roles within their peer group. Children find ways to play in, mold, and claim public space as their space while also seeking ways to engage with the dominant adult community in the neighborhood. Children have strong opinions about their neighborhood and want their ideas surrounding community improvement to be taken seriously by adults. Adults could better cultivate a child-friendly neighborhood by soliciting children's participation in community decisions. Children had reasonable ideas for making their neighborhood more useable. These ideas included the addition of casual dining options like a sandwich shop or a pizza by the slice store. Small, single-lot parks also enhance children's ability to access outdoor play space and fully use their neighborhood.

\section{Safely Independent: Negotiating Dangers}

Children's ability to independently navigate the neighborhood is an area of contention between children and their guardians. Children 8 years old and older tend to be the ones dipping their toes into these independent geographies; no children in the $5-7$ year old age bracket discuss areas of independent travel in their neighborhood. The children in this study have few places they are able to access in the neighborhood completely on their own. Their guardian-free geographies expand when accompanied by peers and could include several blocks. Children are hesitant to report experiences that feel unsafe to them while they were traveling independently or with peers. This is largely due to a fear of their autonomy being restricted as the result of these experiences. Instead of turning to their parents for support, children often turn to their friends and appeared to handle these unsafe situations competently. Children make plans to travel in groups, predetermine their routes and the locations of available adults who could help in an emergency, and are quick to leave situations if they feel unsafe. These findings are consistent 
with other literature on children's geographies and children's ability to navigate risk in the United Kingdom (Valentine, 2004; Woolley \& Griffin 2014).

I often watched children engaged in monitoring each other's safety and behavior in situations when I was the only adult present. This was especially apparent with siblings. During one walking interview, 10-year-old Vasek called to his sister to hurry when crossing a street, as he saw a car turning into her path. In a similar incident, a 12-year-old girl grabbed her 10-yearold sister by the shirtsleeve and pulled her back from the street, angrily whispering "Be careful! You have to look or we're not gonna to get to walk around here any more!" This social phenomenon seems to be critical for all members of the group. If a child is behaving in an unsafe manner and is injured, the entire group seems to be held accountable by their guardians. Children must demonstrate an ability to identify and prevent unsafe situations in order to gain a larger adult-free neighborhood geography. This monitoring also seems to provide a sense of friendship and safety to the children involved. The knowledge that their friends will look out for them, combined with the reduced need to inform their parents of unsafe situations, makes the children equally invested in this protective dynamic, which is beneficial to all members of the group.

Children in this study often differentiated between their perceived safety concerns of heavy car traffic and unfamiliar men with what Katz (2006) calls "terror talk." Terror talk, stranger-danger discourse used to heighten parents' fears, is the main tool used in this marginalization of children from public spaces. Terror talk refers to the public discourse distorting the fears of parents by heightening awareness of extreme and rare events of violent crimes against children in public space. This leads parents to heavily restrict children's access to public spaces, despite the evidence that children are at significantly greater risk of violence being perpetrated against them in private spaces, especially the home (Corsaro, 1997; Valentine, 2004; 
Woolley and Griffin, 2014). Valentine (2004) argues that, "socio-spatial marginalization is a feature of western childhoods." One 9-year-old in the Arcadia neighborhood discussed the reality of her primary barrier to accessing the neighborhood being her mother's anxieties rather than any tangible safety risk:

Researcher: Are there things that you wish were different? Would there be something that we could change that would make it safer or easier for you to walk around [here]?

Amelia, age 9: Well, my mom is always worried about that. There's always people on our street and we live right next to a highway so it's kind of crazy. So, my mom is always worried about me. I always have to have very good contact, whenever I'm at home alone or something like that. So, just, feel like maybe there's something that could maybe change my mom's thoughts on being so protective [laughter]."

Researcher: Interesting! So you feel safe, but the thing that would be great for you to change would be your mom's feelings of safety.

\section{Amelia: Yeah!}

Amelia identifies her perceived safety concerns of strangers and heavy car traffic as things to be aware of, but also as things that she feels capable of handling. In my interview with Amelia the only thing she requested to be different about her neighborhood was her mother's relationship to it. This was consistent in other children's accounts of seeking independent access to public space in the Arcadia neighborhood. It was not strangers or traffic that limited them, but rather their parents' anxieties that kept them dependent on adults in order to access their community.

This is not to say that young children are cavalier about their vulnerability in public space. Children are aware of the truth behind "terror talk" rhetoric. They also understand that these safety threats have a real impact on their ability to access public space. Two siblings who had some of the largest independent neighborhood ranges discussed this tension between what 9-year-old Silvie calls “evil people” and 10-year-old Vasek's understanding of the realistic level of danger he and his sister are in while in public space: 
Researcher: Do you guys think you get to walk around more places by yourself than your friends get to?

Vasek, age 10: Yeah. We get to walk more places by ourselves.

Silvie, age 9: I'm not mad at their parents. I know they're trying to keep them safe.

Researcher: What do you think they're trying to keep them safe from?

Silvie: You never know. There are people. There are evil people around here. There is a chance that your kid can be kidnapped.

Vasek: My mom said this is a pretty safe place.

Researcher: Do you guys feel you know how to handle those situations? Have you talked about that with your parents at all? Or are there ways you keep yourself safe when you're walking around?

Silvie: We do it. If we get lost from our parents, or without parents, and somebody's trying to attack you, never follow them if they want you to do it because they may harm you in a place where nobody can see you. There's also the thing if you really do need help...you do, do, do need help, our mom says, look for a person with a kid because those people are probably safer than other people without kids.

Vasek: Or security guards. More security guards could be better here.

Both Vasek and Silvie struggle to untangle how safe they actually are in their neighborhood.

These intelligent, independent children also backed up Valentine's (2004) conclusion that children can competently respond to unsafe situations in public space. Silvie's plan to seek out an adult with children is an appropriate response to an unsafe situation, as is Vasek's idea about seeking out a security guard. Silvie and Vasek told me they have brainstormed safety strategies with their parents. This open relationship with their parents has fostered street smarts for both of these children, along with larger independent neighborhood ranges. Silvie and Vasek also expressed the most willingness to tell their parents about experiencing unsafe situations, as they didn't feel their independence would be hampered by this disclosure. Children want to access public space with their peers and with adults they trust. Children are also socially aware enough 
to understand their vulnerability as children, and understand which strangers are most likely to help them.

\section{What Makes Spaces Important}

Children in Arcadia see their neighborhood as defined by the spaces that allow them to autonomously form and maintain social bonds with family members, friends, and non-familial adults. These young residents use public space in their neighborhood as sites to create and participate in community. It is then no surprise that children value spaces based on the social and emotional attachments formed in the neighborhood.

The importance of spaces that are sites of social and emotional attachment was best demonstrated by 8-year-old Chloe's depiction of her neighborhood. Chloe spent 45 minutes drawing the neighborhood coffee shop, and nothing else. Her artwork was detailed and thoughtful. Her map is not included because it has identifying information on it.

Researcher: Can you tell me about your drawing of [the coffee shop]? It seems like when I asked about a place that you like to go, you thought of [the coffee shop]. Is that true?

Chloe, age 8: Yeah. I like brownies and food and the lady at the counter. My dad takes me there and he gets me a hot chocolate.

Researcher: Oh, your dad takes you and gets you a hot chocolate. It sounds like it is a place that you get special time with your dad?

Chloe: Yeah!

Chloe, like the other children in this study, focused on public spaces where they received special attention from their parents. Maintaining the caregiver and child bond by going to the coffee shop, playing soccer on the school fields, or roller skating down neighborhood side streets helps the child form bonds with the community as well as the caregiver. Children come to value the shops, fields, and streets because of the positive emotional connections formed there. 
Children also value places and things of physical sustenance. Interestingly, children in Arcadia heavily emphasized trees, edible plants, and flowers as things that were critical to their neighborhood.

Researcher: What would you guys think if there weren't trees in the neighborhood? Are trees important?

Emily, age 6: Yeah! You couldn't breathe!

Researcher: What if you could still breathe? Do you think are just fun to have around or not so much?

Emily: Yeah, you can climb trees

Researcher: [Audrey], what about you? If there was something that left your neighborhood, what would you be upset about leaving the neighborhood?

Audrey, age 6: I need the flowers.

Researcher: You need flowers?

Audrey: Yeah. They're just pretty.

Trees and flowers offer clean air, beauty, and a place to play. Children saw the important role plants played in their physical health along with the aesthetic contribution plants bring to their communities. Children placed value on plants even if they lived further away from the more lush, middle-class section of the neighborhood. One child who lives on the edge of Arcadia in what her aunt described as a low-income "housing project" wished for more flowers in her part of the neighborhood:

Researcher: If you guys could add something to your neighborhood to make it better or more fun, what would it be? What would you add?

Tiana, age 5: I will add a flower, to make it funner, because you get to smell flowers. Tiana's cousin, 5-year-old Caleb, piggybacked off Tiana's wish for more flowers and requested a community garden near their housing project that would grow:

Caleb, age 5: "Food! Healthy food. Like watermelon or grapes." 
Trees are also part of children's culture and folklore in Arcadia. Children assign social significance to trees in their neighborhood. "The Stinky Tree," "Evan's Uncle's Climbing Tree," and "The Twisty Tree" are important landmarks for children and also mark important places. One tree on the school grounds is a memorial tree with fabric strips tied to the branches. These pieces of fabric represent "wishes." Several children somberly guided me to this tree and it appears in the majority of children's photographs. They call it the Wishing Tree.

Researcher: Can you tell me about the wishing tree?

Rose, age 12: All of those things have real wishes on them. But it's also...

Hailey, age 10: One of our classmates passed away in first grade, so his name is right there.

Rose: It's like his tree.

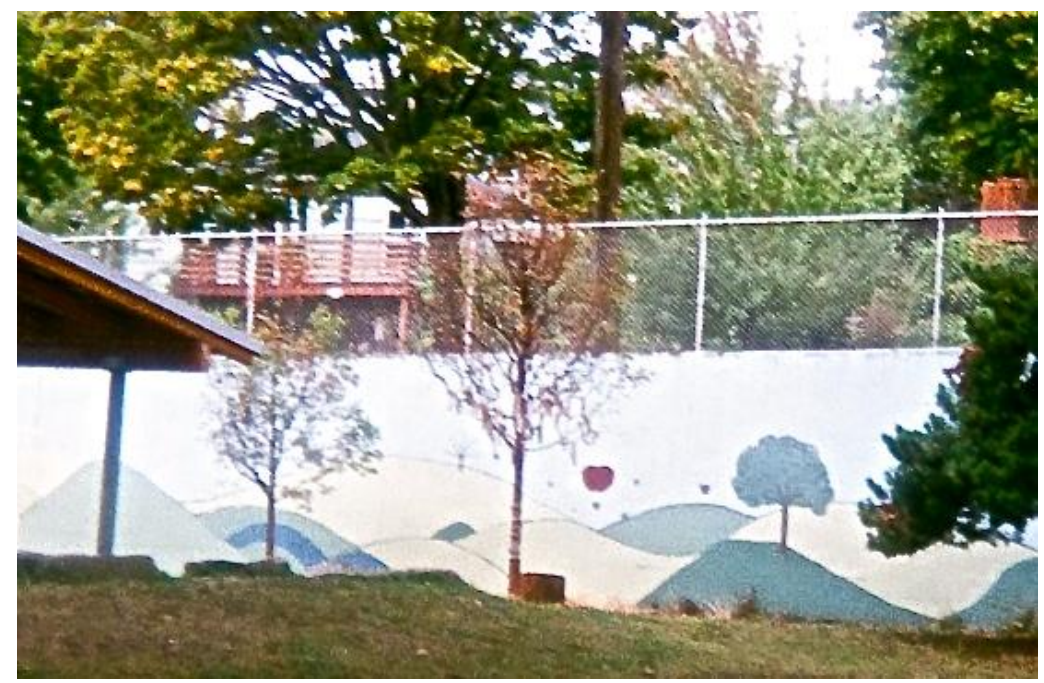

Wishing Tree. Photo by: Rose, age 12

The Wishing Tree is an important place for children to process the death of another child with their peers. This public place is also a space where young children grapple with complicated concepts of their own mortality, their own hopes, and the wishes of others around them. This public memorial asks for a specific child to be remembered as part of the Arcadia community. It is also a space where many local children feel they are also acknowledged as valuable and 
important to the community too. Trees and other plants hold social significance in children's culture, making them highly valued parts of the Arcadia neighborhood.

Children value public space in the Arcadia neighborhood based on how that place sustains them physically, emotionally, and socially. Places that foster physical and emotional wellness are valued within children's social worlds. Public spaces that allow for caregiver and child bonding activities, autonomous free play, or offers acknowledgment to children's important role in the community are particularly important spaces to children in Arcadia. Children actively seek out and request places that improve their quality of life, such as community gardens and safe play areas.

\section{Conclusion}

Children have a complex understanding of community, public space, and "the neighborhood." They are not merely a projection of adult members' values, use cases, or definitions. Children define public space in the neighborhood as areas in which communities are formed and maintained. Children's definition of the neighborhood is more flexible than the literal definition of neighborhood boundaries used by adults. Children's definition of the neighborhood is based on feelings of strong social bonds nested within the context of the child's age, personality, and sense of autonomy. Children use public space to play, to formulate their own peer cultures, and to participate actively in the community at large. Children value public spaces that sustain them physically, emotionally, and socially. Rather than seeing "the neighborhood" as a set of standard geographic boundaries, children see a layered, evolving mixture of physical spaces and social connections. Children take pride in their roles as cocreators of public space in their neighborhoods and desire to be seen as competent, valuable members of their communities. 
The children in this study spoke highly of their neighborhood and believe their adults generally want to foster an equitable community. Though children in Arcadia seem to thrive with community gardens, play spaces, strong local library, and a community culture that emphasizes a family-friendly atmosphere, the community is not serving all child and adult residents. These under-served residents either self-identify or are identified by the local children as lower or working class residents. Notably the only two Black children in this study were also the most vocal about inaccessible neighborhood services, especially access to healthy food. With this legacy of the Black ghettos in the Albina District as the backdrop, I found that the children in this study seek socially just solutions to address the working poor, disabled, and homeless people in their communities. These findings show an advanced understanding of equality and fairness. The children's desire for a socially equitable neighborhood and their suggestions of communitywide modifications also supports the literature that states that children are active social actors who understand the role and impact of society on an individual's life (Bourke, 2107; Corsaro, 1997). Children in Arcadia want their roles in society to be forces of positive change. Further research that investigates children's roles in creating socially equitable communities is warranted and would support the policy goals underlying the U.N. Convention on the Rights of the Child. Children also wish to have greater input in community planning decisions especially in regards to the local school, community gardens, and playgrounds. A handful of older children also hold strong opinions about housing development in the neighborhood and wish to be involved in local action with the influx of new housing developments. Four children, ages 9-12 years old, lamented the demolition of historic Arcadia homes and churches as developers make way for newly built "mega mansions." Children expressed sorrow over the history of their neighborhood being erased, as 12-year-old Rose explained, “I don't really like that they're 
tearing down stuff. We had an old church at the end of the block and they built some big, grey box at the end instead." Another child explained that the influx of new residents coupled with new construction is, "too busy for my ears." This supports the idea of children as active social actors who both participate in and help to create their communities (Corsaro, 1997). Children struggle to define a way in which they could have the power to impact community planning decisions, yet they do desire a platform where the adults in their community can hear their concerns and opinions.

Children in Arcadia feel largely ignored by the adult community when it comes to listening to children's voices on decisions that affect them. The Arcadia Neighborhood Association could rectify this by better enabling youth participation. This could look like holding community meetings at accessible times, such as weekend afternoons, and also setting aside time during the meeting for youth to bring specific requests or issues to the attention of the community. These changes would help the neighborhood conduct itself in accordance with The Bill of Rights for the Children and Youth of the City of Portland and Multnomah County, which states that children have the right to voice their opinions on community matters. It is time to acknowledge children's inherent personhood. By incorporating children's thoughtful, insightful, and sincere concerns in our neighborhood design and planning process, we create communities where equal value is placed on all members' experiences of shared spaces. 


\section{$\underline{\text { References }}$}

Bradley, R. H., and R. F. Corwyn. 2002. "Socioeconomic Status and Child Development." Annual Review of Psychology 53: 371-399.

Bhosale, J., Duncan, S., Stewart, T., Chaix, B., Kestens, Y., \& Schofield, G. (2017). Measuring children's independent mobility: comparing interactive mapping with destination access and licence to roam. Children's Geographies, 1-12.

Bourke, J. (2016). Children's experiences of their everyday walks through a complex urban landscape of belonging. Children's geographies, 1-14.

Clark, A. (2004). The mosaic approach and research with young children. Sage.

Clark, A. (2010). Young children as protagonists and the role of participatory, visual methods in engaging multiple perspectives. American Journal of Community Psychology, 46(1-2), $115-123$.

Chawla, L., \& Malone, K. (2003). Neighbourhood quality in children's eyes. Children in the city: home, neighbourhood and community, 118-141.

Crossman, A. (2016, September 18). Content Analysis: Method to Analyze Social Life Through Words, Images. Retrieved January 26, 2017, from http://sociology.about.com/od/C_Index/g/Content-Analysis.htm

Corsaro, W. A. (1997). The sociology of childhood (pp. 4-5). Thousand Oaks, CA: Pine Forge Press.

Elsley, S. (2004). Children's experience of public space. Children \& Society, 18(2), 155-164.

Gammon, R. (2011, September 07). Why Curfews Don't Work | Politics \& Government | Oakland, Berkeley, Bay Area \& California | Robert Gammon. Retrieved March 23, 2017, from http://www.eastbayexpress.com/oakland/why-curfews-dontwork/Content?oid=2979555

Griffin, K. M., Lahman, M. K., \& Opitz, M. F. (2014). Shoulder-to-shoulder research with children: Methodological and ethical considerations. Journal of Early Childhood Research, 1476718X14523747.

Katz, C. (2006). Power, space, and terror: social reproduction and the public environment. The politics of public space, $105-122$.

Loebach, J., \& Gilliland, J. (2016). Neighbourhood play on the endangered list: examining patterns in children's local activity and mobility using GPS monitoring and qualitative GIS. Children's geographies, 14(5), 573-589.

Mitra, Raktim, et al. "Do parental perceptions of the neighbourhood environment influence 
children's independent mobility? Evidence from Toronto, Canada." Urban Studies (2014): 0042098013519140.

Mehta, S. (2015, November 20). There's Only One Country That Hasn't Ratified the Convention on Children's Rights: US. Retrieved January 17, 2017, from https://www.aclu.org/blog/speak-freely/theres-only-one-country-hasnt-ratifiedconvention-childrens-rights-us

National Criminal Intelligence Service (2002) Paedophile crime, including on-line child abuse. http://www.ncis.co.uk/ukta/2002/threat9.asp

Our Bill of Rights: Children \& Youth | Multnomah County. Retrieved from https://multco.us/multnomah-youth-commission/our-bill-rights-children-youth

Randall, D. (2012). Revisiting Mandell's 'least adult' role and engaging with children's voices in research. Nurse Researcher, 19(3), 39+.

Tranter P., Whitelegg J. (1994) Children's Travel Behaviours in Canberra: Car-dependent lifestyles in a low-density city, Journal of Transport Geography, 2(4), 265. http://dx.doi.org/10.1016/0966-6923(94)90050-7 Google Scholar

Schoeppe, S., Tranter, P., Duncan, M. J., Curtis, C., Carver, A., \& Malone, K. (2016). Australian children's independent mobility levels: secondary analyses of cross-sectional data between 1991 and 2012. Children's Geographies, 14(4), 408-421.

Stephenson, A. (2009). Horses in the sandpit: Photography, prolonged involvement and 'stepping back' as strategies for listening to children's voices. Early Child Development and Care, 179(2), 131-141.

Spitzer, N. (1986) The children's crusade. Atlantic, 257, June, 18 - 22.

United Nations, 1992, Agenda 21 (New York: United Nations)

U.S. Census Bureau. (n.d.). 2000 and 2010 Census Profile. Retrieved from https://www.portlandoregon.gov/oni/article/376021

Valentine, G. (2004). Public space and the culture of childhood. Aldershot: Ashgate.

Woodson, S. E. (2007). Performing youth: Youth agency and the production of knowledge in community-based theatre. Representing youth: Methodological issues in critical youth studies, 284-303

Woolley, H. E., \& Griffin, E. (2015). Decreasing experiences of home range, outdoor spaces, activities and companions: changes across three generations in Sheffield in north England. Children's Geographies, 13(6), 677-691. 


\section{Appendix A: Poster for Recruitment}

\section{Draw Your Arcadia!}

Sept. 12th $\mathbb{E} 15$ th, $4-5 \mathrm{pm}$

Sept. 17th, 3:30-4:30pm

The Library
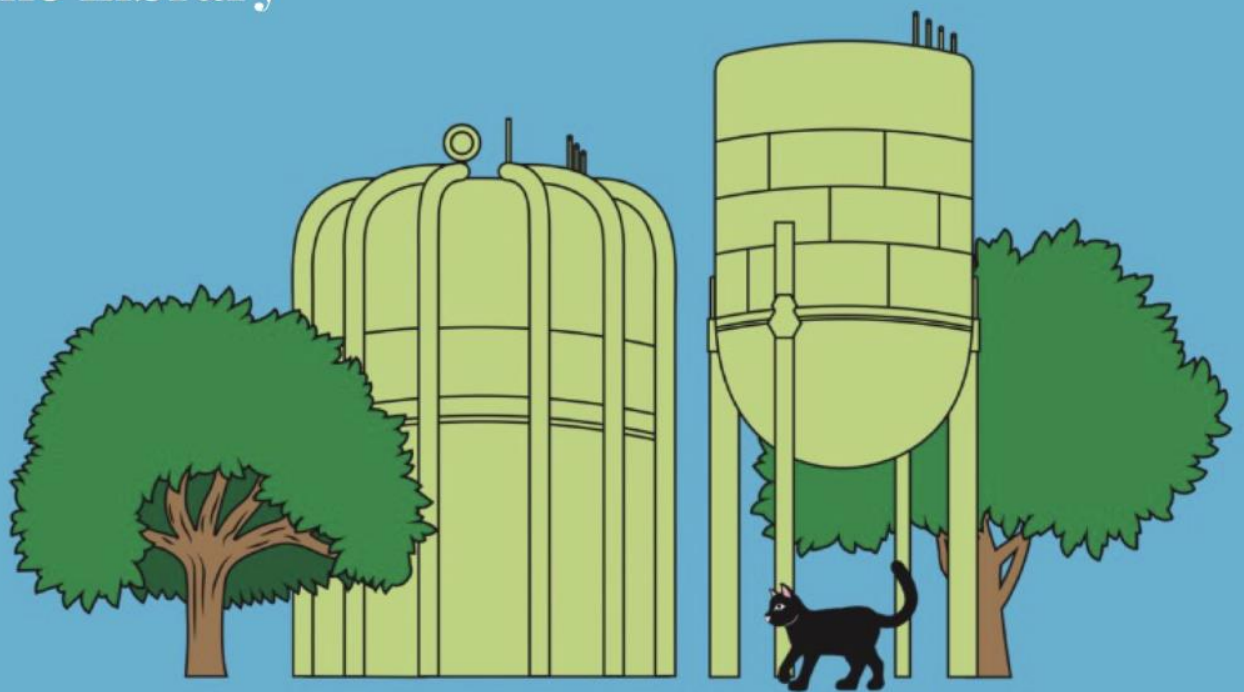

\section{Looking for kids to draw maps of Arcadia}

My name is Sophie Biddle, and I'm a senior in the University Honors College at Portland State University. For my thesis I'm doing a case study on the Arcadia neighborhood, specifically focusing on how kids ages 5-13 use, see, and value urban spaces. I want a large part of my data to come from maps depicting the Arcadia neighborhood drawn by local children. All data will be kept confidential and children will be welcome to keep their map. All supplies will be provided.

\section{Questions? Contact Sophie: sbiddle@pdx.edu}




\section{Appendix B: Letter to Neighborhood Parents}

Hello,

My name is Sophie Biddle. I am a senior in the University Honors College at Portland State University. In the upcoming weeks I will be doing research for my senior thesis in the [Arcadia] neighborhood.

I'll be exploring how kids between the ages of 5 and 13 years old use, see, and value public space in the [Arcadia]. This research will help make better, child-friendly urban planning policy that is based off of kids' voices and experiences.

I will be hosting a public mapmaking project for kids at the [...] Library on September 12th and 15 th from 4-5pm, and September 17th from 3:30-4:30pm. Please feel free to stop by and bring your little mapmaker. I will also host "walking interviews" with kids, where they will take photos of places in Sabin and we will talk about why those places are picture-worthy.

If you have a child who is interested in either one of these projects and would like more information about my research, please contact me at: sbiddle@pdx.edu or my faculty advisors Amy Coplen: acoplen@pdx.edu and Dr. Samuel Henry at henrys@pdx.edu.

Thank you for your time. I look forward to learning more about your neighborhood.

Best,

Sophie Biddle

sbiddle@pdx.edu

(602) 653-6624 